\title{
APPLICATIONS OF NEURAL ADAPTIVE CONTROL TECHNOLOGY
}


WORLD SCIENTIFIC SERIES IN ROBOTICS AND INTELLIGENT SYSTEMS

Editor-in-Charge: C J Harris (University of Southampton)

Advisor: $\quad$ T M Husband (University of Salford)

Vol. 1: Genetic Algorithms and Robotics - A Heuristic Strategy for Optimization (Y Davidor)

Vol. 2: Parallel Computation Systems for Robotics: Algorithms and Architectures (Eds. A Bejczy and A Fijany)

Vol. 3: Intelligent Robotic Planning Systems ( $P C-Y$ Sheu and $Q$ Xue)

Vol. 4: Computer Vision, Models and Inspection ( $A D$ Marshall and $R$ R Martin)

Vol. 5: Advanced Tactile Sensing for Robotics (Ed. H R Nicholls)

Vol. 6: Intelligent Control: Aspects of Fuzzy Logic and Neural Nets ( $C J$ Harris, $C$ G Moore and $M$ Brown)

Vol. 7: Visual Servoing: Real-Time Control of Robot Manipulators Based on Visual Sensory Feedback (Ed. K Hashimoto)

Vol. 8: Modelling and Simulation of Robot Manipulators: A Parallel Processing Approach (A Y Zomaya)

Vol. 9: Advanced Guided Vehicles - Aspects of the Oxford AGV Project (Eds. S Cameron and P Probert)

Vol. 10: Cellular Robotics and Micro Robotic Systems ( $T$ Fukuda and T Ueyama)

Vol. 11: Recent Trends in Mobile Robots (Ed. YF Zheng)

Vol. 12: Intelligent Assembly Systems (Eds. M Lee and J J Rowland)

Vol. 14: Intelligent Supervisory Control: A Qualitative Bond Graph Reasoning Approach ( $H$ Wang and $D$ A Linkens)

Vol. 15: Neural Adaptive Control Technology (Eds. R Żbikowski and K J Hunt)

Vol. 17: Applications of Neural Adaptive Control Technology (Eds. J Kalkkuhl, $K J$ Hunt, R Żbikowski and A Dzieliński)

Forthcoming:

Vol. 13: Sensor Modelling, Design and Data Processing in Confined Environments ( $M$ D Adams)

Vol. 16: Advances in Robotics \& Automation for Hazardous Environment (Eds. $P$ Lever and F Y Wang) 
World Scientific Series in Robotics and Intelligent Systems - Vol. 17

\title{
APPLICATIONS OF \\ NEURAL ADAPTIVE \\ CONTROL TECHNOLOGY
}

\author{
Editors \\ JENS KALKKUHL \\ KENNETH J HUNT \\ Daimler-Benz AG \\ RAFAŁ ŻBIKOWSKI \\ ANDRZEJ DZIELIŇSKI \\ Univ. Glasgow
}




\section{Published by}

World Scientific Publishing Co. Pte. Ltd.

P O Box 128, Farrer Road, Singapore 912805

USA office: Suite 1B, 1060 Main Street, River Edge, NJ 07661

UK office: 57 Shelton Street, Covent Garden, London WC2H 9HE

\section{Library of Congress Cataloging-in-Publication Data}

Applications of neural adaptive control technology / editors, Jens Kalkkuhl.

p. $\quad \mathrm{cm}$. -- (World Scientific series in robotics and intelligent systems; vol. 17)

Includes bibliographical references and index.

ISBN 9810231512

1. Adaptive control systems. 2. Neural networks (Computer science)

I. Kalkkuhl, Jens. II. Seires.

TJ217.A66 1997

629.8'36--dc21

97-19177

CIP

\section{British Library Cataloguing-in-Publication Data \\ A catalogue record for this book is available from the British Library.}

Copyright (C) 1997 by World Scientific Publishing Co. Pte. Ltd.

All rights reserved. This book, or parts thereof, may not be reproduced in any form or by any means, electronic or mechanical, including photocopying, recording or any information storage and retrieval system now known or to be invented, without written permission from the Publisher.

For photocopying of material in this volume, please pay a copying fee through the Copyright Clearance Center, Inc., 222 Rosewood Drive, Danvers, MA 01923, USA. In this case permission to photocopy is not required from the publisher.

This book is printed on acid-free paper.

Printed in Singapore by Uto-Print 


\section{Preface}

This book comprises the results of the second workshop on Neural Adaptive Control Technology, NACT II, held on September 9-10, 1996 in Berlin. The workshop was organised in connection with a three-year European Union funded Basic Research Project in the ESPRIT framework, called NACT, a collaboration between Daimler-Benz (Germany) and the University of Glasgow (Scotland).

The NACT project, which began on 1 April 1994, is a study of the fundamental properties of neural network based adaptive control systems. Where possible, links with traditional adaptive control systems are exploited. A major aim is to develop a systematic engineering procedure for designing neural controllers for nonlinear dynamic systems. The techniques developed are being evaluated on concrete industrial problems from within the Daimler-Benz group of companies.

The aim of the workshop was to bring together selected invited specialists in the fields of adaptive control, nonlinear systems and neural networks. The first workshop (NACT I) took place in Glasgow in May 1995 and was mainly dedicated to theoretical issues of neural adaptive control. Besides monitoring further development of theory, the NACT II workshop was focused on industrial applications and software tools. This context dictated the focus of the book and guided the editors in the choice of the papers and their subsequent reshaping into substantive book chapters. Thus, with the project having progressed into its applications stage, emphasis is put on transfer of theory of neural adaptive engineering into industrial practice. Therefore the contributors are both renowned academics and practitioners from major industrial users of neurocontrol.

Chapter 1 of the book gives an overview of further developments and results in the NACT project. The first three sections of this chapter contain a résumé of the main goals and the project rationale. Also, the engineering background is sketched with a brief outline of the industrial problems to which the NACT techniques are being applied. This is followed by four technical sections. First, the multi-dimensional sampling approach to neural network modelling is outlined. Then issues of adaptive networks of local models and controllers are discussed. This is followed by an account of geometric control techniques using neural network plant models. The technical content of each part of the work is logically placed within the overall framework and the interrelationships between the individual parts are stated. Particular attention is given to the experimental evaluation of the techniques developed within the NACT framework. First experimental results for a test application, a longitu- 
dinal automotive dynamics control problem, are given.

Chapters 2 and 3 are devoted to monitoring recent developments in the theory of neural adaptive control technology. Focus is on two major strains of theoretical research: neural control based on input-output descriptions of nonlinear systems, and the resulting stability and robustness issues; second, heterogeneous and hybrid types of nonlinear control systems. Chapter 2 is written by Hassan K. Khalil, a renowned contributor to the fields of nonlinear systems theory and adaptive control. It analyses paradigms of nonlinear control, adaptation and learning, issues that are of paramount importance for neural adaptive control. The chapter centres on input-output (NARX type) descriptions of nonlinear systems. Neural networks using both linear as well as nonlinear parameterisation are discussed and the resulting stability and convergence issues for the closed-loop control system are addressed. In particular, H.K. Khalil addresses the practically important subject of nonlinear adaptive output feedback control where only measurements of the plant outputs are used. Chapter 3 by G.A. Rovithakis et al. encompasses continous-time neural adaptive control schemes and their application to the control of discrete-event systems, where a case study of the control of a wood processing plant demonstrates the efficiency of the technique.

Chapters 4 to 9 deal with various industrial applications of neural adaptive controllers. The applications range from biochemical systems and process control to robotics and power circuit control. Chapter 4 by C. Szepesvári and A. Lörincz is a benchmark study on the high precision neurocontrol of a chaotic Bioreactor. This is followed by the presentation of an approach for sensorbased motion planning for a pneumatic robot arm where neural networks are used for mapping obstacles (Chapter 5, M. Zeller et al.). The control of an experimental heat exchanger based on neural networks with distributed dynamics is reported in Chapter 6 by M. Ayoubi et al. Following the space-frequency function approximation approach of Sanner and Slotine in Chapter 7, adaptive control and estimation using Gaussian radial basis functions is analysed and validated for two examples, a robotic manipulator and a nonlinear level control (J. P. Fredsted). Practical issues in the introduction of adaptive neural controllers into an industrial automation evironment are discussed by $\mathbf{A}$. Hambrecht and D. Neumerkel in Chapter 8. The book ends with Chapter 9, a case study on the application of neural networks for controlling electrical power circuits in railway propulsion systems (S. Scheffler, J. Böcker). 


\section{Contents}

Preface $\quad$ V

Neural Adaptive Control Technology 1

K. J. Hunt, J. C. Kalkkuhl, Th. Göttsche, R. Żbikowski,

A. Dzieliński, P. J. Gawthrop, T. A. Johansen, H. Fritz

Nonlinear Control: Adaptation and Learning

H. K. Khalil

A Neural Adaptive Control Technique for Manufacturing

Scheduling

G. A. Rovithakis, V. I. Gaganis, S. E. Perrakis,

V. S. Kodogiannis, M. A. Christodoulou

Approximate Inverse-Dynamics Based Robust Control

Using Static and Dynamic Feedback

C. Szepesvári, A. Lörincz

Vision-Based Robot Motion Planning Using a Topology

Representing Neural Network

M. Zeller, K. Schulten, R. Sharma

Dynamic Multi-Layer Perceptron Networks: Application to the Nonlinear Identification and Predictive Control of a

Heat Exchanger

M. Ayoubi

Adaptive Control Using Localised Radial Basis Function

Networks

J. P. Fredsted

Implementation of Neural Adaptive Control Strategies for

Industrial Automation

A. Hambrecht, D. Neumerkel

Application of Neural Networks for Control of Four-Quadrant Converters in Railway Propulsion Systems

S. Scheffler, J. Böcker

Index 